\title{
THE ROLE OF STRATEGIC THINKING IN IMPROVING THE QUALITY OF AUDIT AND ITS CONTRIBUTION TO DETECTING THE RISKS OF FRAUD
}

\author{
Assistant teacher. Jaafar Abdel-Hussein Hilloalkabei, Prof.Safaa Ahmed muhammad Al-Ani \\ Baghdad University - College of Management and Economics \\ Accounting Department
}

DOI: $10.37648 / \mathrm{ijrssh} . v 10 \mathrm{i} 03.016$

Received: $08^{\text {th }}$ June, 2020; Accepted:20 $0^{\text {th }}$ June, 2020; Published: $13^{\text {th }}$ July,2020

\begin{abstract}
Strategic thinking helps auditors to improve the quality of audit, which contributes to making better assessments of the risk of fraud, as the phenomenon of fraud is one of the negative phenomena that can be expressed as a social scourge and its presence in any society is evidence of its distance from adherence to the values and provisions of religion and public ethics.Therefore, many economic and accounting researches have long sought to model strategic thinking through a hierarchy of levels of strategic thinking. Therefore, the current research aims to demonstrate the contribution of strategic thinking to improving the quality of audit and its contribution to detecting the risks of fraud. The research reached a number of conclusions, the most important of which is a role for strategic thinking in improving the quality of audit, which contributes to detecting the risks of fraud. The most important recommendations were the necessity for the auditing profession to use strategic thinking because of its role in improving the quality of auditing to detect the risks of fraud.
\end{abstract}

Keywords: strategic thinking, audit quality, fraud risk

\section{INTRODUCTION}

The audit offices seek to achieve a high level of audit quality to disclaim their responsibilities to the parties benefiting from the audit results, as the high-quality audit procedures help the offices to avoid professional and legal penalties due to any violation or failure in the audit work by emphasizing compliance with local and international auditing standards and rules of professional conduct and related instructions and laws.Therefore, many economic and accounting researches have long sought to model strategic thinking through a hierarchy of levels of strategic thinking that contains beliefs in terms of strategic logic to be used in the audit process as required and in the highest quality possible because it is expected that the external users of the financial statements depend on the outputs of the audit process represented in the high-quality report of the auditor 
because they depend in making their decisions on this report and that its performance with the required quality supports its reputation, fame and competitive position in its field of work as it can improve the performance of the audit team by applying the strategic thinking method, which improves the quality of the audit to detect Fraud risk.

First topic: Research Methodology and Previous Studies

Second topic: The concept of strategic thinking and its role in improving the quality of auditing to detect the risks of fraud - a conceptual approach

Third topic: Measuring the role of using strategic thinking to improve the quality of auditing and its contribution to detecting the risks of fraud - Practical approach.

Fourth topic: Conclusions and recommendations

\section{FIRST TOPIC : RESEARCH METHODOLOGY AND PREVIOUS STUDIES}

First - Research methodology

\section{Research problem}

The use of audit programs, and in particular traditional programs, makes auditors less able to change audit procedures effectively, which poses a problem in detecting fraud, so the research problem can be formulated in the following questions:

1- There was no significant relationship to the strategic thinking technique in detecting the risk of fraud at a significant level of (5\%).

2- There was no significant relationship to the strategic thinking technique in detecting the risks of fraud by improving the quality of the audit.

\section{Significance of the study}

The significance of the research is that it discusses issues related to the continuity of the auditing profession and the ability of the auditor to detect fraud risks, as well as the clear implications of strategic thinking in detecting fraud for companies listed on the Iraq Stock Exchange.

3. Study objectives: The current research aims to achieve the following goals:

A- Presenting and discussing the concept of strategic thinking as a contemporary concept and explaining its role in improving the quality of auditing to detect the risks of fraud.

B- Measuring the role of using strategic thinking to improve the quality of audit and its contribution to detecting fraud risks.

\section{Hypothesis of the study}

The research is based on the following main hypotheses:

1- There is a significant relationship between the strategic thinking techniqueand the detection ofrisks of fraud at a significant level of $(5 \%)$.

2- There is a significant relationship between the strategic thinking techniqueand the detection of the risks of fraud by improving the quality of the audit.

\section{Research approach and data collection methods}

The researchers relied on the theoretical and practical approaches of the research as follows:

1- Theoretical approach: The two researchers relied on the available literature oflocal, Arab and foreign books, periodicals, MSc. theses, $\mathrm{PhD}$ dissertations.

2- Practical-applied approach: The research relied on a number of means to obtain the required data and information, the most important of which are:

A- The auditors' bulletin issued by the auditing and auditing profession board.

B- Financial reports of the economic units listed on the Iraq Stock Exchange.

C- The questionnaire represented by a questionnaire for Iraqi audit firms and offices.

D- Laws of the practice of the profession and the laws of the Securities Commission and suspensions issued by the Securities Commission. 
6. Research population and sample: The research population is represented in:

A- Population and sample of Iraqi audit firms and offices.

B- Population and sample of economic units listed on the Iraq Stock Exchange.

C- Board of Supreme Audit of Iraq.

\section{Second: Previous studies and the contribution made} by the current research

\section{1- Previous studies}

A- The study of (Al-Sultani, B 2014) entitled (The Extent of Commitment of Auditors in Iraq to Detect Cases of Deception and Fraud according to the International Auditing Standard (240) A comparative analytical research in a sample of banks listed on the Iraq Stock Exchange" a research submitted to the Higher Institute.

The study aimed to reach aspects of professional responsibility related to the performance of auditors, and to identify the extent of auditors' compliance with international auditing standard (240) "Responsibility of auditors related to fraud in the audit of financial statements." The research also reached a number of conclusions, the most important of which is the complexity of the processes that occur in the economic unit has found ways for fraud perpetrators to achieve their goal.

B- The study of (Dahdouh and Sabbagh, 2016) entitled "The Extent of Auditors' Commitment to Assess the Factors Related toMaterial Misstatements Resulting from Fraud - A Field Study at the Syrian Securities Commission and Financial Markets", a published research.

This study aimed at identifying the extent of auditors' commitment to assess the risk factors of material misstatements resulting from fraud, and to achieve the aim of the study a questionnaire was developed that included the risk factors of material misstatements resulting from fraud and classified according to international auditing standards to two main groups which are factors related to fraudulent financial reports and others related to misallocation of assets; this is to identify the extent of the auditors' commitment to evaluate those factors within the research community represented in the auditors, and the study found that there is an average commitment to assess the risk factors of material errors resulting from fraudulent financial reports.

C- The study of (Wilks, Zimbelman: 2004) entitled: Using Game Theory and Strategic Reasoning Concepts to Prevent and Detect Fraud:

This study aimed to identify the ideas related to detecting, preventing and limiting fraudulent financial reports, as the study reviews theoretical and experimental research included in game theory and relying on concepts of social psychology, judgments, decision-making as well as auditing to determine the improvements that occurred in the process of practicing auditing profession. The research also reached a number of conclusions, the most important of which is that the focus of the audit process on preparing strategic thinking contributes to making adjustments to the audit criteria. These amendments will facilitate the use of auditors for strategic thinking in the audit process. As the strategic thinkingtechnique emphasizes three tasks of the audit process: assessing fraud risks, planning audit and implementing the audit plan. The most important recommendations of the study were the necessity of making changes to the current auditing standards in order to be more effective in detecting and reducing fraud.

D- The Study of (Hoffman \&Zimbelman: 2012) entitled: Do Strategic Reasoning and Brainstorming Help Auditors Change Their Standard Audit Procedures in Response to Fraud Risks

The research aims to show the effects of using two methods on auditing planning decisions in the face of high risks of fraud, namely strategic thinking and brainstorming. Both methods are expected to lead auditors to modify planned audit procedures more effectively. This is through the use of a team of experts to detect fraud to determine effective modifications to the fraud audit plan. Then, expert recommendations are used to evaluate the effectiveness of auditors' audit plans in the event that both methods are used together or 
without the two methods used together. The research also reached a number of conclusions, the most important of which is that the use of each method separately leads to highly effective adjustments to standard auditing procedures as well as that the combination of the two methods is more effective in the audit process.

2- The contribution made by the current research

The present study is characterized by the importance of being one of the first studies in the Iraqi environment that tried to link the methods of psychology represented in the strategic thinking technique and the auditing profession and clarify its role in improving the quality of the audit and its contribution to detecting the risks of fraud.

\section{SECOND TOPIC : THE CONCEPT OF STRATEGIC THINKING AND ITS ROLE IN IMPROVING THE QUALITY OF AUDITING TO DETECT THE RISKS OF FRAUD - A CONCEPTUAL APPROACH}

First: Strategic thinking

1- The concept of strategic thinking

The concept of strategic thinking is "an individual activity that benefits the economic unit by detecting the competitive strategies that will achieve an important competitive position for it versus its competitors" (Goldman \&et al.2009: 406). Strategic thinking has been known as a special way of thinking concerned with addressing insight, which results in an integrated view of economic unity through a structural process resulting from the good use of creativity in shaping strategic directions (Mintzberg, 1994:175).

The two researchers believe that the thinking process aims to formulate an integrated strategy related to the integrative structure of business-oriented decisions and the use of resources with rationality and awareness and to define the field of competitive excellence and the development of business strategies that have a greater chance of success and adding value to economic unity.

\section{2- Importance of strategic thinking}

Strategic thinking is a mental and cognitive process that the individual uses to look at the problems at which decision-making is required and requires dealing with it after evoking the actual situation that the individual encounters with extreme accuracy. To win the most competitive positions in light of its limited resources, as strategic thinking is goal oriented and focuses on the future in an accurate way (Ridgley, 2012:8)

\section{3- Characteristics of strategic thinking}

Strategic thinking is a proactive and reflective thinking that is valuable for everyone within society, and it is especially necessary for individuals who wish to become successful entrepreneurs and gives strategic thinking self-confidence to work in a dynamic and competitive environment where the ability to strategic thinking can help the economic unit to determine the methods that develop confident expectations and reduce the uncertainty of business decisions, therefore strategic thinking is seen as an essential component in creating and maintaining a competitive advantage (Alssaty, 2007:66)

4- Levels of strategic thinking within the scope of the audit

A- Strategic Thinking of the lowest (zero) degree

Thinking of the lowest degree means that auditors take into account the conditions that affect them directly without affecting others, and that both the audit risk model and the theory of decisions refer to the thinking of the lowest (zero) degree in the same previous sense. When the auditor is associated with thinking of the lowest (zero) degree, he takes into account, in a simplified manner, only his motives, that is, it focuses on the audit process fees, costs of obtaining the sample and its fines or penalties, so the auditor assesses the risk of errors assuming that the behavior of the audited party is not affected by the audit procedures used and heperforms the audit process to maximize the trade-off between cost and return (Wilks \&Zimbelman, 2004:175). 


\section{B- Strategic thinking of the first degree}

Strategic thinking of the first degree means that the auditor takes into account the circumstances that directly affect the audited party, so the auditor assumes that the auditing parties use the thinking of the lowest (zero) degree and the auditor on this according to the motives of the party or audited parties, when the audited party has motives to conceal the information, the auditor modifies the audit plan to detect this concealment, and when auditing fraud, the auditor does not take into account whether the audited party has the ability to anticipate the auditor's behavior and here the auditor is more likely to use the familiar traditional audit approaches known by the economic unit under auditing. In light of this type of thinking, the auditor does not take into account whether the parties subject to the audit expect the changes that the auditor makes to his plan (Zimbelman\& Waller, 1999:135).

\section{C- Strategic thinking of the highest degree}

It occurs when the auditor takes into account how the audited parties can expect the auditor's behavior and under this type of thinking the auditor realizes that the audited party will expect the audit procedures and will design the fraud so that it can be sufficient to conceal it from the audit procedures and here the auditor will modify the procedures to detect concealment (Zimbleman\& Waller, 1999:135) The following figure shows the levels of strategic thinking in the audit.

\section{Second: Improving the quality of auditing to detect fraud risks}

\section{1- Concept of audit quality}

The quality of audit is an important topic in the auditing profession and researchers in the auditing profession have been trying since 1981 to define the quality of auditing and how to measure it and study its various dimensions and (De Angelo) was one of the first researchers who developed a definition for the quality of auditing as he defined it as "The possibility of the auditor to detect the material distortions, errors and gaps in the financial statements of the audited entity, and to report them and record this in the report he issues at the end of the audit process (the auditor's report) (De Angelo, 1981:185)".
(Sakel\&Schonberger, 2015) see that the quality of auditdoes not represent an appropriate audit opinion, but also accounts for the audit process, including technical and audit services aspects, as academics and professional bodies have established comprehensive frameworks for the quality of audit that include many additional aspects and refinement of a model - As these studies also go beyond the idea of linking the quality of audit to the quality of financial reports (Sakel\&Schonberger, 2015:17).

2- The concept of fraud:

Fraud is an uncommon but well-studied crime as it is a frightening and evolving process at the present time and it is often carefully organized and appears in many areas. (Arens et al. 2012) defined fraud as a broad legal concept that is any deliberate deception intended to strip someone of a portionof his properties and rights, either on the scope of auditing the financial statements, fraud is defined as intentional misleading in the financial statements (Arens et al.2012:356) whereas auditing standard No.(SAS No.99) defined fraud as "intentional act by one or more individuals in the Management or those charged with governance, employees, or other parties that involve the use of deception to obtain an unfair or unlawful advantage (Vona, 2011:7).

The researchersdefine fraud as the intention to commit mistakes by manipulating financial statements with the intention of hiding certain features through the use of a work authority to achieve personal benefits at the expense of the economic unit as the fraud practitioner possesses a distinct set of knowledge that the auditor must master this knowledge to encounter the fraud risk and solve any difficulties when encountering it.

\section{3- Theories of fraud}

1- Fraud Triangle Theory

The fraud triangle theory proposed by (Cressey, 1973) represents the basic conceptual framework for factors that together cause or explain an individual's motivations to commit fraud, as well as they provide insight and useful insight into the phenomenon of fraud from a broad point of view, and the fraud triangle theory model includes three sides together establish a misleading behavior that represents the first side of the fraud triangle "pressure or motives for committing fraud 
and deception", and the second side symbolizes the perceived opportunity, the third side symbolizes the justification for the practice of fraud, and the fraud triangle theory can be presented as follows (Marshall \& John, 2018:135-137)(Singleton \& Singleton, 2010:46)

1- Pressure: It is the first side and represents the main motivation for committing fraud as the individual practices fraud because he is exposed to financial or social pressures or problems or any other nature, and it cannot be solved or mitigated in an authorized manner. These financial pressures represent a common incentive for workers who embezzle assets, as employees with increased financial obligations can steal to meet personal financial needs.

2- Opportunity: It is the second side of the fraud triangle, and it relates to the precondition of the individual in order to be able to commit fraud. Fraudulent activities can only be committed when the opportunity is provided for the individual to solve or reduce the pressure or problem of the experienced in an unauthorized manner but frighteningly, since the one who practices fraud always has the knowledge and opportunity to commit fraud.

3- Justification: It is the third element in the fraud triangle and it is the psychological mechanism that explains the fraudsters not abstaining from committing fraud and consider that their behavior is acceptable, as the direction of the Management towards controls and ethical behavior of workers and managers can justify the theft of assets, when the Management resorted to using fraud to mislead customers, by shipping the goods that were sold, they can feel that it is acceptable to behave in the same way by manipulating the expenses or reports submitted by them.

\section{2- Fraud rhomboid theory}

The design of the fraud rhomboid theory is a new addition to the fraud triangle theory. In a particular fraud theory model, a fourth element called (capability) has been added to the first three elements of fraud and (Wolf and Hermanson, 2004) indicates that it is especially from the pressures or incentives with an opportunity to commit frauds as well If there is a justification for doing so, it is unlikely that fraud will occur unless the fourth element (i.e. capability) is also present i.e. the individual who committed the fraud must have the skill and ability to commit fraud (Wolfe and Hermanson, 2004:41).

Fourth: The contribution of strategic thinking to improving the quality of auditing to detect fraud risks

(Wilks \&Zimbelman, 2004) emphasizes that strategic thinking can contribute to improving the quality of auditing by helping auditors to make better assessments of fraud risks, as auditors can start their assessments by looking at whether signals to the hypothesis of the fraud triangle (i.e. pressure and opportunities) indicate a type of low risk of fraud. When these signals indicate that there is no low risk of fraud, auditors in this case must search for (justification) signals that indicate in the same side, so the auditing standards that govern fraud risk assessments should address the ability of the subject to scrutinize evidence manipulation in order to influence auditors' perceptions of fraud risk (Wilks and Zimbelman, 2004:177) and that auditors largely agree that it is easy to hide the justification signs followed by opportunity signals, so you should not rely on references that indicate a low risk of fraud and that can Management has to manipulate it in order to assess fraud risk. Therefore, a risk assessment policy that encourages strategic thinking must be followed by urging auditors to think about the management's ability to conceal fraud risk information (Wilks \&Zimbelman, 2004:178).

(Wilks \&Zimelman, 2004) assert that the use of strategic thinking method in detecting and reducing fraud takes a high position in the auditing profession, which improves the quality of auditing, and this is confirmed by modern regulations that aim to improve the ability of auditors to detect fraud and can help auditors to perform three main tasks by using strategic thinking to improve the quality of audit.

THIRD TOPIC : MEASURING THE ROLE OF USING STRATEGIC THINKING TO IMPROVE THE QUALITY OF AUDIT AND ITS CONTRIBUTION TO DETECTING THE RISKS OF FRAUD -PRACTICAL APPROACH

This research aims to statistically test the main research hypotheses, whereby the two researchers detailed the 
sample responses on the basis of each axis and to find out the sample responses about the paragraphs in each dimension will use the ratios, frequencies, weighted arithmetic means and standard deviations and to know the direction of the responses we will compare the arithmetic mean with the hypothetical mean if the value of the arithmetic mean is greater than the value of the hypothetical mean, this means that the directions of the responses of the sample members were directed towards agreement, but if the value of the arithmetic mean is smaller than the value of the hypothetical mean, this means that the responses are directed towards disagreement, and the value of the hypothetical mean is calculated in the following way:

Hypothetical mean $=$ Set of scale alternative/number of alternatives

Hypothetical mean $=(5+4+3+2+1) / 5=3$

First: Analysis of the results of the questionnaire response

In this paragraph, the statistical results of the data presented in the questionnaire will be analyzed, using a set of statistical methods in order to test the validity of the research hypothesis adopted by the researchers. This paragraph will be divided as follows:

1- Analysis of the results of the response to the paragraphs of the Strategic Thinking axis: This axis contains several paragraphs as follows:

1. The responses of the sample revealed that strategic thinking directs positive behavior towards developing and encouraging creative work with an agreement of (96.8\%) and arithmetic mean of (4.54).

2. Sample responses revealed that strategic thinking contributes to accomplishing the required actions in a renewed and developed manner with an agreement of (92.8\%) and arithmetic mean of (3.87).

3. The sample agreed that strategic thinking helps in the ability to think quickly in different circumstances and in an arithmetic mean of (4.22) with an agreement of (82.4\%).

4. The responses showed that strategic thinking contributes to adopting new ideas and methods for solving business problems with an arithmetic mean of (4.42) and an agreement of (90.4).

5. The sample confirmed that strategic thinking contributes to identifying weaknesses or shortcomings in work with an agreement of (80.8\%) and an arithmetic mean of (4.17).

6. Strategic thinking contributes to preparing plans to face the expected crises at work, and this is what the sample confirmed by an agreement of $(85.6 \%)$ and an arithmetic mean of (4.31).

7. It stimulates strategic thinking in presenting a large number of unfamiliar ideas in a relatively short time, this is what the sample emphasized and with an agreement of $(88.4 \%)$ and an arithmetic mean of (4.10).

8. The sample confirmed that strategic thinking, which is characterized by meaningful and logical thinking, contributes to defining the main tasks of economic units with an agreement of $(85.6 \%)$ and an arithmetic mean of (4.21).

9. Strategic thinking, which possesses the skill of strategic thinking, contributes to overcoming business obstacles, and this is what the sample agreed upon with an agreement of (82.4\%) and an arithmetic mean of (4.11).

10. The sample agreed that strategic thinking encourages an increase in the ability to present more than one idea in a short time period with an agreement of (88.8\%) and an arithmetic mean of (4.25).

11. Strategic thinking, using modern scientific methods, helps to understand and analyze different information and this is what the sample confirmed by an agreement of (90.4\%) and an arithmetic mean of (4.38).

12. The responses of the sample confirmed that strategic thinking encourages studying the ideas together instead of studying them individually, which makes them touch their value in the long term, with an agreement of $(85.6 \%)$ and an arithmetic mean of (4.18).

13. Strategic thinking, through thinking in a timely manner, helps clarify important matters that find the gap between the reality of the present and the intention of the future, and this is confirmed by the responses of the sample, with 
an agreement of $(83.2 \%)$ and an arithmetic mean of (4.17).

14. The sample confirmed that the diversity in strategic thinking contributes to determining competition options through thinking methods and purposes with an agreement of (87.2\%) and an arithmetic mean of (4.19).

15. Opportunistic thinking of strategic thinking contributes to seizing smart opportunities by anticipating emergency environmental changes, and this is confirmed by the sample responses of $(80.8 \%)$ and an arithmetic mean of (4.12).

From the previous analysis, it is clear that:

1- Auditors prefer to use strategic thinking that directs positive behavior towards the development and encouragement of creative work, as strategic thinking encourages increasing the ability to present more than one idea in a short time period, which helps in providing ideas in a timely manner, and this facilitates clarification of the important issues that bridge the gap between reality of the present and the intention of the future.

2- Auditors prefer diversity in strategic thinking that contributes to determining competition options through methods and purposes of thinking, and which contributes to seizing smart opportunities by anticipating emergency environmental changes.

3- Analysis of results in response to paragraphs of the quality of audit: This axis contains several paragraphs, as follows:

1. The quality of the audit is a service provided by the audit offices related to the quality of the outputs of the audit process. This is confirmed by the literature of the audit profession and by an agreement of (94.4\%) and by an arithmetic mean of (4.42) so the level of the response to this paragraph was within the very high level.

2. The sample confirmed that the quality of the audit relates to the extent to which the standards and professional codes of conduct set by the Institute of American Accountants are met, with an agreement percentage of (92\%) and an arithmetic mean of (4.36).
3. The quality of the audit is related to the quality of the financial reports as well as the quality of the profits with an agreement percentage of $(72.8 \%)$ and an arithmetic mean of (3.94).

4. The sample agreed that the quality of the audit is related to the characteristics of the various auditors within the audit firms, including the auditor's experience, skills, leadership and ethical values, with a percentage of agreement of $(94.4 \%)$ and an arithmetic mean of (4.42) and the response for this paragraph was within the very high level.

5. The sample confirmed that the quality of the audit is related to factors outside the audit company, which include the business relationship between the auditors and other major participants in the audit market, especially the audit clients and the Audit Committee, with a percentage of agreement of $(76.8 \%)$ and an arithmetic mean of (4.05) which is greater than the value of the hypothetical mean and the response forthis paragraph was within the high level.

6. The quality of the audit contributes to determining the amount of time spent in the audit process, and this is what the sample confirmed with a percentage of agreement of (78.4\%) and an arithmetic mean of (4.17) which is greater than the value of the hypothetical mean and the response for this paragraph was within the high level.

7. The responses of the sample agreed that the large size of the entity subject to the audit affects the quality of the audit process with a percentage of agreement of (78\%) and an arithmetic mean of (3.79).

8. The sample confirmed that the good reputation of the auditor contributes positively to the quality of the audit process, with a percentage of agreement of $(86.6 \%)$ and an arithmetic mean of (4.27).

9. The size of the auditor's wages negatively affects the quality of the auditing process in the absence of a practical method for determining it, and this is what the sample agreed upon, with an agreement of (66.4\%) and an arithmetic mean of (3.81). 
10. The sample emphasized that the independence of the auditor positively affects the quality of the audit process with percentage of agreement of $(92 \%)$ and an arithmetic mean of (4.41) which is greater than the value of the hypothetical mean, and the answer to this paragraph was within the high level.

11. The scientific and professional qualification of the auditor affects the quality of the audit, and this is what the sample agreed upon with a percentage of agreement of $(94.4 \%)$ and an arithmetic mean of (4.57) which is greater than the value of the hypothetical mean. The answer to this paragraph was within the very high level.

12. The sample's responses confirmed that the consultancy services provide important benefits to the audit process, which enhances the quality of the audit, with a percentage of agreement of (84.8\%) and an arithmetic mean of (4.24).

13. The professional skepticism of auditors who make judgments more skeptical about their nature contributes to the quality of the audit, and this is confirmed by the sample responses, with percentage of agreement of (80.8\%) and an arithmetic mean of (4.08).

14. The sample agreed that the leadership of the audit partner is considered important to achieve the quality of the audit, as it contributes to estimating the material deviations, according to a percentage of agreement of $(83.2 \%)$ and an arithmetic mean of (4.08).

15. The professional specialization affects the quality of the audit, as it distinguishes between the audit services provided by the audit offices and the consulting services provided by the same offices, and this is what the sample agreed upon with a percentage of agreement (89.6\%) and with an arithmetic mean of (4.27) .The response to this paragraph was within the very high level.

From the previous analysis, it is clear that:

1- The auditors explained that the quality of audit is a service provided by the audit offices and is related to the quality of the outputs of the audit process, so the quality of the audit is linked to the extent to which the standards and professional codes of conduct set by the American Institute of Accountants are met.

2- The auditors agreed that the independence of the auditor positively affects the quality of the audit process, and therefore the scientific and professional qualification of the auditor affects the quality of audit, in addition to that the consulting services provide important benefits to the audit process, which enhances the quality of audit.

3- Analysis of results in response to the fraud risk axis: This axis contains several paragraphs as follows:

1. The literature confirmed that fraud is an incorrect accounting estimate resulting from an omission or misinterpretation of facts and by a percentage of agreement of $\left(69.6^{\wedge}\right)$ and an arithmetic mean of (3.28). The response for this paragraph was within the mean level.

2. The responsibility for deterring fraud rests primarily on the administration, and this is confirmed by the sample responses, with a percentage of agreement of (88.8\%) and an intermediate mean of (4.22). The response to this paragraph was within the very high level.

3. The responses of the sample confirmed that the economic units can protect themselves from major frauds by making persistent and continuous effort with a percentage of agreement of $(89.6 \%)$ and an arithmetic mean of (4.30) and the answer to this paragraph was within the very high level.

4. The sample agreed that preventive measures should be put in place to prevent the possibility of fraud risks, wherever possible and with a percentage of agreement of (96.8\%) and an arithmetic mean of (4.45) and the response to this paragraph was within the very high level.

5. The responses of the sample confirmed that fraud is through choosing the accounting policy that the standards allow, in order to achieve a better picture of the financial statements, with a percentage of agreement of $(70.4 \%)$ and an arithmetic mean of (3.87).

6. Fraud is through the introduction of some artificial deals either by manipulating the amounts of the financial position or to move 
the profits between accounting periods and this is what the sample responses agreed upon and with a percentage of agreement $(81.6 \%)$ and an arithmetic mean of (4.10) and the response to this paragraph was within the high level.

7. The sample agreed that fraud is by manipulating the timing of deals with the goal of specifying a specific year to report profits or charging them with losses with an agreement of $(80.2 \%)$ and an arithmetic mean of (4.08) and the response level to this paragraph was within the high level.

8. The sample agreed that the fraud process includes internal and external parties with a percentage of agreement of $(88 \%)$ and an arithmetic mean of (4.16). The response to this paragraph was within the high level.

9. The use of deliberate and intentional practices is from the act of fraud and this is what the sample agreed upon with a percentage of agreement of $(88 \%)$ and an arithmetic mean of (4.16) which is greater than the value of the hypothetical mean, and the answer to this paragraph was within the high level.

10. The sample agreed that the presence of unusual pressures from inside and outside the economic unit to achieve several goals leads to the fraud process and with a percentage of agreement of $(84 \%)$ and an arithmetic mean of (4.14) and the response to this paragraph was within the high level.

11. The value of the arithmetic mean for the paragraph (The flexibility provided by the accounting principles in the test among the accounting methods and procedures contributed to the presence of frauds) reached (3.89) and this is greater than the value of the hypothetical mean, that is, the directions of the sample responses were directed towards agreement strongly with a percentage of $(31.2 \%)$ and towards agreement with a percentage of $(39.2 \%)$, the answer for this paragraph was within the high level.

12. Maximizing management rewards in the economic unit leads to the selection of accounting methods that will increase the net result of the activity and this led to the presence of fraud operations, and this is what the sample agreed upon with a percentage of agreement of $(72.8 \%)$ and an arithmetic mean of(4.02).

13. The fraud triangle theory explains the individual's motives for committing the fraud process, and this is confirmed by the sample responses, with a percentage of agreement of (77.6\%) and an arithmetic mean of (4.03).

14. The responses of the sample agreed that the ability represents the position regarding the presence of the traits or skills and capabilities required for a person to commit fraud and with a percentage of agreement of (74.4\%) and an arithmetic mean of (3.96) which is greater than the value of the hypothetical mean, that is, the directions of the sample responses were directed towards the agreement strongly with a percentage of $(27.2 \%)$ towards the agreement with a percentage of (47.2\%) and the responseto this paragraph was within the high level.

15. The sample confirmed that placing a person or his position within the economic unit provides the ability to create occupation or an opportunity for fraud with a percentage of agreement of $(73.6 \%)$ and an arithmetic mean of (3.94).

From the previous analysis, it is clear that:

1. Fraud is an incorrect accounting estimate resulting from an omission or misinterpretation of facts, especially since the responsibility to deter fraud lies primarily with management, as economic units can protect themselves from major frauds by making persistent and continuous effort.

2. Fraud is through the selection of the accounting policy permitted by the standards in order to achieve a better picture of the financial statements, and this is through the introduction of some artificial deals either to manipulate the amounts of the financial position or to move the profits between accounting periods.

3. The fraud triangle theory explains an individual's motives for committing fraud. As for ability, it represents the attitude towards 
having the traits, skills, and abilities a person needs to commit fraud.

Second: Testing the study hypotheses statistically, the following was used:

1- Simple linear regression: To test the relationship of the independent variable (strategic thinking method) in the dependent variable, this represents (fraud risk detection).

2- Multiple linear regression: to test the relationship of the independent variable (strategic thinking method) in the dependent variable, which is (fraud risk detection).
3- Path analysis: to test the effect of the intermediate variable of previous hypotheses.

\section{1- Testing the first major hypothesis:}

Null hypothesis: (There is no significant relationship to the method of strategic thinking in detecting the fraud risks at a significance level of (5\%).

Alternative hypothesis: (There is a significant relationship for the strategic thinking method in detecting the fraud risks at a significant level of (5\%).

Table (1) shows the results of simple linear regression about the effect of strategic thinking technique on detecting fraud risks

\begin{tabular}{|l|l|l|l|l|l|l|}
\hline $\begin{array}{l}\text { Constant } \\
\text { value }\end{array}$ & $\begin{array}{l}\text { Beta } \\
\text { coefficient } \\
\text { value }\end{array}$ & $\begin{array}{l}\text { Coefficient of } \\
\text { determination } \\
\text { value }\end{array}$ & $\begin{array}{l}\text { Calculated F } \\
\text { value }\end{array}$ & $\begin{array}{l}\text { Degree of } \\
\text { freedom } \\
\text { F value }\end{array}$ & $\begin{array}{l}\text { Tabulated } \\
\text { Significance }\end{array}$ \\
\hline 1.55 & 0.59 & 0.29 & 49.04 & 123.1 & 3.88 & $\begin{array}{l}\text { There is an } \\
\text { effect }\end{array}$ \\
\hline
\end{tabular}

This table was prepared by the researcherdepending on the results of the SPSS program.

Through table (1) the calculated F value (49.04) is greater than its tabulated value of (3.88) at the level of significance of (0.05), degree of freedom of (123.1). This means the rejection of the null hypothesis and acceptance of the alternative hypothesis, that is, there is a significant relationship to the strategic thinking method in detecting the risks of fraud, and since the beta coefficient signal is positive, this means that the effect is positive (direct relationship), and the value of the coefficient of determination (0.29) and this means that (29\%) of the changes that occur in detecting the risks of fraud can be explained by the method of strategic thinking, and the value of beta coefficient $(0.59)$ has reached a positive value and this means that when one unit of strategic thinking is changed, there will be an increase of (59\%) in detecting the fraud risks, and the regression equation is:

$\mathrm{Y}=1.55+0.59 \times 1$

$\mathrm{X} 1=$ Strategic thinking technique

\section{2- Testing the second main hypothesis:}

Null hypothesis: (There is no significant relationship to the strategic thinking technique in detecting the risks of fraud through quality auditing).

Alternative hypothesis: (There is a significant relationship to the strategic thinking technique in detecting fraud risks through quality auditing).

Table (2) shows the results of the path analysis

\begin{tabular}{|c|c|c|c|c|c|c|c|}
\hline $\begin{array}{l}\text { Independent } \\
\text { variable }\end{array}$ & $\begin{array}{l}\text { Intermediate } \\
\text { variable }\end{array}$ & $\begin{array}{l}\text { Dependent } \\
\text { variable }\end{array}$ & $\begin{array}{l}\text { Direct } \\
\text { effect }\end{array}$ & $\begin{array}{l}\text { Indirect } \\
\text { effect }\end{array}$ & $\begin{array}{l}\text { Total } \\
\text { effect }\end{array}$ & $\begin{array}{ll}\text { Value } & \text { of } \\
\text { coefficient } & \text { of } \\
\text { determination } \%\end{array}$ & $\begin{array}{l}\text { Calculated } \mathrm{F} \\
\text { value }\end{array}$ \\
\hline Strategic & Quality & Detection of & 0.120 & 0.414 & 0.534 & 0.60 & 182.09 \\
\hline
\end{tabular}




\begin{tabular}{|l|l|l|l|l|l|l|l|}
\hline $\begin{array}{l}\text { thinking } \\
\text { technique }\end{array}$ & audit & fraud risks & & & & & \\
\hline
\end{tabular}

The calculated $F$ value has reached (182.09), which is greater than its tabulated value of (3.03) at a significance level of (0.05) and the degree of freedom and this means that there is a significant relationship for the strategic thinking technique in detecting the risks of fraud through the quality of the audit, and the value of the coefficient of determination has reached $(0.60)$ and this means that $(60 \%)$ of the changes that occurred in detecting the risks of fraud are caused by the change in the strategic thinking technique through the quality of audit, the value of the direct effect has reached $(0.120)$ whereas the value of the indirect effect has reached (0.414) and we note that the indirect effect is greater than the direct impact and this indicates that the quality of the audit has an important role with strategic thinking in the impact on detecting fraud risks.

\section{FOURTH TOPIC : CONCLUSIONS AND RECOMMENDATIONS}

\section{First: Conclusions}

1- The use of strategic thinking contributes in directing positive behavior towards developing and encouraging creative work, as strategic thinking encourages increasing the ability to present more than one idea in a short time period, which helps in presenting ideas in a timely manner, and this facilitates clarification of the important matters that bridge the gap between the reality of the present and the intention of the future.

2- The quality of audit is a service provided by the audit offices and linked to the quality of the outputs of the audit process, so the quality of audit is linked to the extent to which the standards and professional codes of conduct set forth by the American Institute of Accountants are met.

3- The independence of the auditor positively affects the quality of the audit process, and therefore the scientific and professional qualification of the auditor affects the quality of the audit, in addition to that the consulting services provide important benefits to the audit process, which enhances the quality of audit.

4- Diversity in strategic thinking contributes in determining competition options through methods and purposes of thinking, which contributes to seizing smart opportunities by anticipating emergency environmental changes.

5- Fraud is an incorrect accounting estimate resulting from an omission or misinterpretation of facts, especially since the responsibility to deter fraud rests primarily with management, as economic units can protect themselves from major frauds by making persistent and continuous effort.

6- Fraud is through the selection of the accounting policy permitted by the standards in order to achieve a better picture of the financial statements, and this is by entering some industrial deals by either manipulating the amounts of the financial position or by moving the profits between accounting periods.

\section{Second: Recommendations:}

1- The necessity of developing training audit programs specialized in the factors of strategic thinking for auditors, especially the courses held by the Board of Supreme Audit of Iraq and the various audit offices.

2- The necessity of using strategic thinking that directs positive behavior towards developing and encouraging creative work.

3- All auditors should be involved in strategic thinking, which improves the quality of audits to detect fraud risks.

4- The necessity of enriching the principle of participation in expressing the auditor's neutral technical opinion.

5- The need to respect the opinions of other auditors and to know their opinions.

6- The need to stimulate scientific research in highlighting other areas through which strategic thinking in the field of auditing can benefit. 


\section{SOURCES}

1- Al-Sultani, Muntaha Abdul-Jassim (2014) The extent of the auditors' commitment in Iraq to detect cases of fraud and fraud according to the international auditing standard (240) - A comparative analytical study in a sample of banks listed on the Iraq Stock Exchange, research submitted to the Arab Institute of Certified Public Accountants, it is part of the requirements for obtaining a public accounting certificate.

2- Dahdouh, Hussein Ahmed and Al-Sabbagh (2016) The extent of the auditors' commitment to assess the risk factors of material errors resulting from fraud, a field study at the Syrian Commission on Financial Markets and Securities "published research, Damascus University Journal of Economic and Legal Sciences - Volume 22 First Issue.

3- Wilks, T. Jeffrey, Zimbelman, Mark F., (2004) Using Game Theory and Strategic Reasoning Concepts to Prevent and Detect Fraud, journal Accounting Horizons, Vol. 18, No. 3.

4- Hoffman, v. b., ;zimbelman,m.f.,(2012) How strategic reasoning and brainstorming can help auditors Detect Fraud?, the accounting review, Vol.6, No2 .

5- Goldman, Peter, et al.(2009), Financial Services Anti-Fraud Risk and Control Workbook, Published by John Wiley \& Sons, Inc., Hoboken, New Jersey, Printed in the United States of America, First Printing.

6- Mintzberg, H., (1994), The Fall and Rise of strategic planning, Harvard Business Review, Jan-Feb.

7- Ridgley, Stanley K.(2012) Strategic Thinking Skills Course Guidebook, Printed in the United States of America, , First published.

8- Hamel, G.\&Prahalad, C., (2003), competing for the Future, Harvard Business Rrwiew, on point, Printed in the United States of America, july-august, 1edition.

9- Alsaaty, Falih M.(2007), Entrepreneurs: Strategic Thinkers In Search Of Opportunities, Journal of Business \& Economics Research, Volume 5, Number 2.

10- ZIMBELMAN, MARK FAND. WALLER, WILLIAM S(1999) An Experimental Investigation of AuditorAuditee Interaction under Ambiguity, Journal of Accounting Research, Vol. 37.

11- Wilks, T. Jeffrey, Zimbelman, Mark F., (2004) Using Game Theory and Strategic Reasoning Concepts to Prevent and Detect Fraud, journal Accounting Horizons, Vol. 18, No. 3.

12- De Angelo , L.E.,(1981) " Auditor Size and Audit Quality, " Journal of Accounting and Economics , NorthHolland Publishing Company, Vol. 3, No. 7.

13- Sakel, Ratzinger- Nicole V. S. / Schonberger, Martin W.(2015) Restricting non-audit services in Europe - The potential (lack of) impact of a blacklist and a fee cap on auditor independence and audit quality, Forthcoming in Accounting in Europe, a journal of the European Accounting Association,Vol. 2.

14- Arens, Alvin A. Elder, Randal J., and Beasly, Mark S (2012), the Auditing and Assurance Services d an Integrated Approach, The International Journal of Accounting, Vol.46

15- Vona, Leonard W.,(2011), The fraud audit : responding to the risk of fraud in core business systems, Printed in the United States of America, Published by John Wiley \& Sons, Inc., Hoboken, New Jersey.

16- Marshall ,Romny B. \&stienbart, Paul john,(2008) Accounting Information System, New York: Prentice Hall Business Publishing, SIXTH Edition.

17- Singleton, Tommie, Aaron J. Singleton (2010), Fraud auditing and forensic accounting, Published by John Wiley \& Sons, Inc., Hoboken, New Jersey, Printed in the United States of America, 4th ed.

18- Wolfe, David\&Hermanson, Dana R (2004) The Fraud Diamond: Considering the Four Elements of Fraud, journal CPA, Vol. 9,No 8. 